INTERNATIONAL JOURNAL
OF
PHARMACEUTICAL SCIENCES
RESEARCH

Received on 13 January, 2013; received in revised form, 05 February, 2013; accepted, 24 April, 2013

\title{
FORMULATION AND EVALUATION OF CONTROLLED RELEASE TABLETS OF MIGLITOL USING COMBINATION OF HYDROPHILIC POLYMERS
}

\section{J. Ashtamkar*, S. Nangude and N. Chugh}

Department of Pharmacy, Vinayaka Missions University, Sankari main Road (NH-47), Ariyanoor, Salem 636308, Tamil Nadu, India

\section{Keywords:}

Miglitol, Hydroxypropyl methylcellulose, Hydroxypropyl cellulose, Hydroxyethyl cellulose, Release Kinetics

\section{Correspondence to Author:}

\section{J. Ashtamkar}

Department of Pharmacy, Vinayaka Missions University, Sankari main Road (NH-47), Ariyanoor, Salem 636308, Tamil Nadu, India

E-mail: jashtamkar@gmail.com

\begin{abstract}
In the present study, Miglitol $25 \mathrm{mg}$ controlled release matrices were prepared by direct compression and in vitro drug dissolution studies were performed to find out the drug release rate and patterns. Hydroxypropylmethylcellulose, Hydroxypropylcellulose and Hydroxyethylcellulose were used as rate controlling polymers. Hydroxypropylmethylcellulose was used as primary rate controlling polymer and effects of addition of Hydroxypropylcellulose and Hydroxyethylcellulose on in-vitro drug dissolution were studied. Tablets were formulated using total polymer content as 30, 35 and 40 percent with 20 percent standard polymer content of Hydroxypropyl methylcellulose in all batches and varying the concentration of Hydroxypropyl cellulose and Hydroxyethylcellulose in the range of 10, 15 and 20 percent. In-vitro drug release was carried out using USP Type II at $50 \mathrm{rpm}$ in $900 \mathrm{ml}$ of acidic dissolution medium ( $\mathrm{pH} \mathrm{1.2)} \mathrm{for} 2$ hours, followed by $900 \mathrm{ml}$ alkaline dissolution medium ( $\mathrm{pH} 7.4$ ) up to 12 hours. Several kinetic models were applied to the dissolution profiles to determine the drug release kinetics.
\end{abstract}

INTRODUCTION: During the last two decades there has been remarkable increase in interest in controlled release drug delivery system. This has been due to various factor viz. the prohibitive cost of developing new drug entities, expiration of existing international patents, discovery of new polymeric materials suitable for prolonging the drug release, and the improvement in therapeutic efficiency and safety achieved by these delivery systems. Now-adays the technology of controlled release is also being applied to veterinary products also.

\begin{tabular}{|l|c|}
\hline QUICK RESPONSE CODE & IJPSR: ICV (2011)- 5.07 \\
\cline { 2 - 2 } & $\begin{array}{c}\text { Article can be accessed } \\
\text { online on: } \\
\text { www.ijpsr.com }\end{array}$ \\
\hline
\end{tabular}

The basic rationale for controlled drug delivery is to alter the pharmacokinetics and pharmacodynamics of pharmacologically active moieties by using novel drug delivery system or by modifying the molecular structure and /or physiological parameters inherent in a selected route of administration ${ }^{1}$.

Hydroxypropylmethylcellulose, Hydroxypropyl cellulose and Hydroxyethylcellulose can be used as matrix materials. The matrix may be tableted by direct compression of the blend of active ingredient and certain hydrophilic carriers or from a wet granulation containing the drug and hydrophilic matrix material ${ }^{2}$.

Diabetes mellitus is a chronic disease that is characterized by disorders in carbohydrate, protein and lipid metabolism. Its central disturbance appears to involve an abnormality either in the secretion of or effects produced by insulin although other factors 
also may be involved. Diabetes mellitus is a metabolic disorder in which carbohydrate metabolism is reduced while that of proteins and lipids is increased.

Miglitol is an oral anti-diabetic drug that acts by inhibiting the ability of the patient to break down complex carbohydrates into glucose. It is primarily used in diabetes mellitus type 2 for establishing greater glycemic control by preventing the digestion of carbohydrates (such as disaccharides, oligosaccharides, and polysaccharides) into monosaccharides which can be absorbed by the body. Miglitol inhibits glycoside hydrolase enzymes called alpha-glucosidase. Since miglitol works by preventing digestion of carbohydrates, it lowers the degree of postprandial hyperglycemia.

Miglitol is systemically absorbed; however, it is not metabolized and is excreted by the kidneys. Also miglitol have a shorter half-life of 2 hours, it requires frequent dosing by oral route. Off various recent techniques for controlling drug release, matrix system offer various advantages of ease of formulation, better control on release profile of drug and better patient compliance.

\section{MATERIALS AND METHODS:}

Materials: Miglitol was obtained as gift sample from Meyer Organics Pvt. Ltd. Thane, Maharashtra.
Hydroxypropyl methylcellulose (HPMC K 15M) was obtained as gift sample from Signet, Mumbai, Maharashtra. Hydroxypropylcellulose and hydroxyethylcellulose were obtained as gift sample from International Specialty Products, Mumbai, Maharashtra. Other materials used were of analytical grade and procured from commercial sources.

Preparation of sustained release matrix tablets of miglitol: Controlled release tablets of miglitol ${ }^{3,4}$ were prepared by direct compression method ${ }^{5}$ using microcrystalline cellulose as directly compressible vehicle. Hydroxypropylmethylcellulose (HPMC K 15M), Hydroxypropylcellulose and Hydroxyethyl cellulose were used as retardant material for preparation of tablets ${ }^{6}$. Other excipients were magnesium stearate as a lubricant and colloidal silicon dioxide as a glidant. For preparation of Controlled release tablets of miglitol, drug and polymer were weighed accurately, all the ingredients were sieved through 40 mesh screen and mixed with other ingredients and the powder mixture was compressed using 16 station rotary tablet compression machine using $5 \mathrm{~mm}$ punches. Tablet compression weight was adjusted to $50 \mathrm{mg}$. In total, 6 formulations containing different amounts of HPC (F1, F2, F3), and HEC (F4, F5, F6) were prepared. The formula for various formulations attempted has been given in Table 1.

\begin{tabular}{ccccccc} 
TABLE 1: COMPOSITION AND PHYSICAL CHARACTERS OF SUSTAINED RELEASE MIGLITOL TABLETS \\
\hline Ingredient & F1 & F2 & F3 & F4 & F5 & F6 \\
\hline Miglitol & 25 & 25 & 25 & 25 & 25 & 25 \\
HPMC K 15M & 10 & 10 & 10 & 10 & 10 & 10 \\
HPC 2M & 5 & 7.5 & 10 & -- & -- & -- \\
HEC 2M & -- & -- & -- & 5 & 7.5 & 10 \\
MCC & 9 & 6.5 & 4 & 9 & 6.5 & 4 \\
Aerosil & 0.5 & 0.5 & 0.5 & 0.5 & 0.5 & 0.5 \\
Magnesium Stearate & 0.5 & 0.5 & 0.5 & 0.5 & 0.5 & 0.5 \\
\hline
\end{tabular}

Physical characterization of Fabricated Tablets ${ }^{7}$ : The quality control tests for the tablets, such as hardness, friability, weight variation etc. were determined using reported procedure. The tablet crushing strength was tested by commonly used Dial tablet hardness tester. Friability was determined by Roche ${ }^{\circledR}$ friabilator (Electro lab Pvt. Ltd., India), which was rotated for $4 \mathrm{~min}$ at $25 \mathrm{rpm}$. After dedusting, the total remaining mass of the tablets was recorded and the percent friability was calculated.
Weight variation was determined by weighing 20 tablets individually, the average weight. Physical characters observed for various batches are given in Table 2.

Estimation of drug content ${ }^{8}$ : An UV/Vis spectrophotometric method based on the measurement of absorbance at $625 \mathrm{~nm}$ in phosphate buffer of $\mathrm{pH} 7.4$ and $0.1 \mathrm{~N}$ alkaline potassium permanganate was used as coloring agent for estimation of miglitol. 
TABLE 2: EVALUATION OF PHYSICAL CHARACTERS OF MIGLITOL TABLETS

\begin{tabular}{ccccc}
\hline Formulation code & Thickness $(\mathbf{m m}) * *$ & Weight variation $(\boldsymbol{\%})$ & Hardness $(\mathbf{K g}) * *$ & Friability (\%)* \\
\hline F1 & $2.52 \pm 0.02$ & 0.05 & $5.25 \pm 0.178$ & $0.05 \pm 0.02$ \\
F2 & $2.54 \pm 0.06$ & 0.16 & $5.16 \pm 0.282$ & $0.13 \pm 0.04$ \\
F3 & $2.51 \pm 0.05$ & 0.23 & $5.38 \pm 0.366$ & $0.17 \pm 0.03$ \\
F4 & $2.53 \pm 0.03$ & 0.08 & $5.52 \pm 0.247$ & $0.09 \pm 0.01$ \\
F5 & $2.52 \pm 0.04$ & 0.15 & $5.29 \pm 0.191$ & $0.15 \pm 0.07$ \\
F6 & $2.56 \pm 0.01$ & 0.28 & $5.47 \pm 0.318$ & $0.22 \pm 0.01$ \\
\hline
\end{tabular}

*All the values are expressed as a mean \pm SD., $n=3$, ** All the values are expressed as a mean \pm SD., $n=6$

From each batch of prepared tablets, 10 tablets were collected randomly and powdered. A quantity of powder equivalent to $150 \mathrm{mg}$ was transferred into a $100 \mathrm{ml}$ volumetric flask, $100 \mathrm{ml}$ phosphate buffer $\mathrm{pH}$ 7.4 was added and the solution was sonication for about $30 \mathrm{~min}$. The solution was made up to $100 \mathrm{ml}$ with alkaline potassium permanganate and phosphate buffer $\mathrm{pH} 7.4$.
Same concentration of the standard solution was also prepared by taking $100 \mathrm{mg}$ of drug in a $100 \mathrm{ml}$ volumetric flask made up to volume with coloring agent and phosphate buffer $\mathrm{pH}$ 7.4.The drug content was estimated by measuring the absorbance of both standard and sample solutions at $625 \mathrm{~nm}$ using UV/Vis spectrophotometer (Systronic 2201). Results are given in Table 3.

TABLE 3: DRUG CONTENT AND IN-VITRO DRUG RELEASE STUDIES OF MIGLITOL TABLETS

\begin{tabular}{ccc}
\hline Formulation code & Drug content $\mathbf{( \% )}$ & Cumulative \% drug release \\
\hline F1 & $98.49 \pm 1.134$ & $85 \pm 0.02$ \\
F2 & $101.27 \pm 1.231$ & $80 \pm 0.08$ \\
F3 & $99.63 \pm 0.840$ & $75 \pm 0.13$ \\
F4 & $99.27 \pm 1.521$ & $89 \pm 0.25$ \\
F5 & $98.98 \pm 0.977$ & $88 \pm 0.28$ \\
F6 & $101.41 \pm 0.760$ & $88 \pm 0.31$ \\
\hline
\end{tabular}

All the values are expressed as a mean \pm SD., $n=3$

In-vitro release studies: The in vitro dissolution studies were performed using USP type 2 dissolution apparatus (paddle) at $50 \mathrm{rpm}$. The dissolution medium consisted of $1.2 \mathrm{pH}$ medium for first 1 hour and for subsequent 11 hours in phosphate buffer $\mathrm{pH}$ $7.4(900 \mathrm{ml})$, maintained at $37 \pm 0.5^{\circ} \mathrm{C}$. The release studies were conducted in triplicate. Aliquot of samples $(5 \mathrm{ml})$ were withdrawn at specific time intervals and drug content was determined spectrophotometrically at $625 \mathrm{~nm}$. Results are tabulated in table 3. Results of in-vitro dissolution studies are shown graphically in Figure 1.

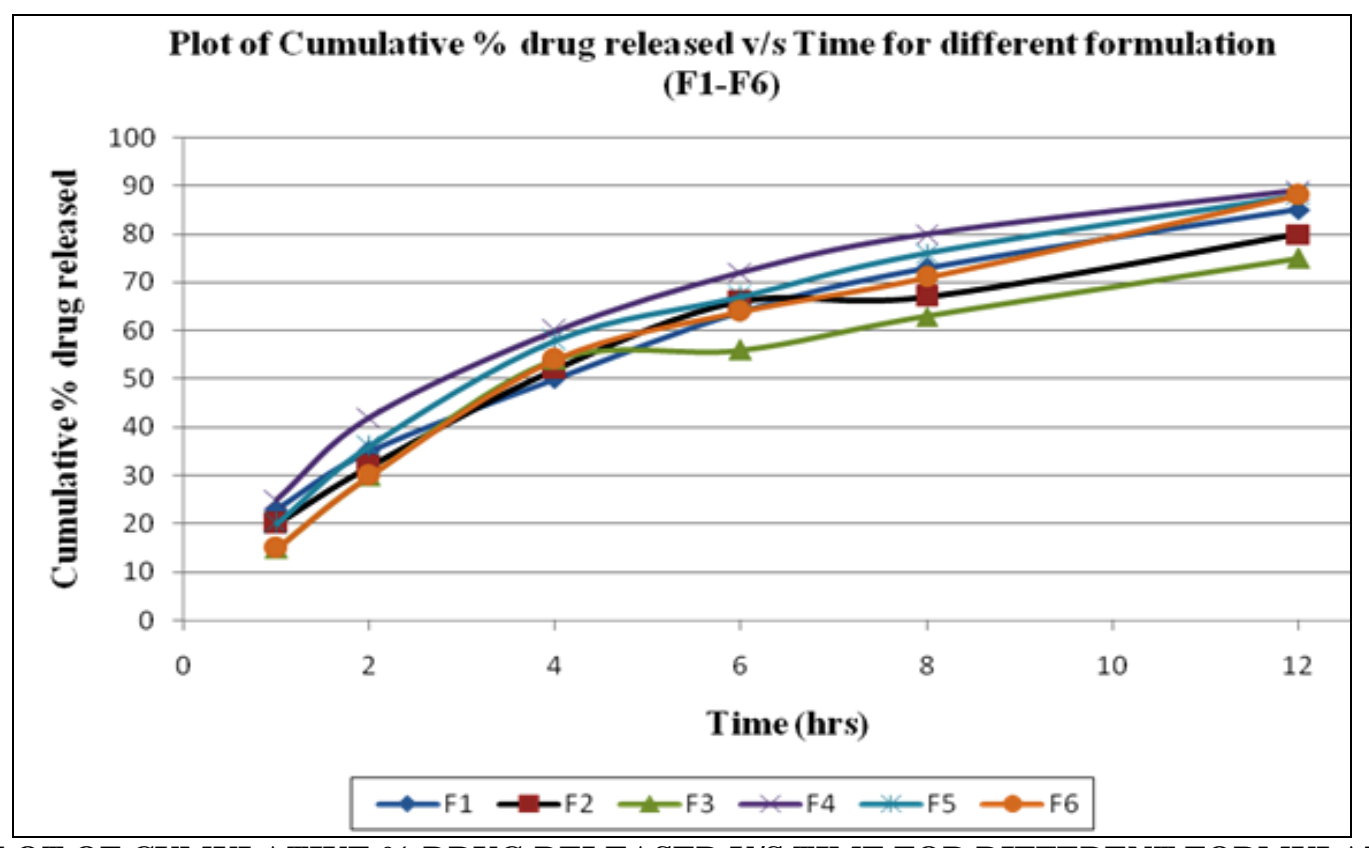

FIGURE 1: PLOT OF CUMULATIVE \% DRUG RELEASED V/S TIME FOR DIFFERENT FORMULATION (F1-F6) 
Kinetics of in-vitro drug release ${ }^{9}$ : In-vitro release data obtained was treated to zero order rate equation, Higuchi's equation and Korsmeyer's- Peppas equation to know precisely the mechanism of drug release from matrix tablet. Release data obtained is treated with following modes of data treatment. Zero order equation - Cumulative percentage drug release vs. Time in hours. First order equation - Log cumulative percentage drug remained vs. Time in hours. Higuchi's Diffusion equation - Cumulative percentage drug release vs. Square root time. Korsmeyer- Peppas equation - Log cumulative percentage of drug release vs. Log time.

Results are tabulated in Table 4: Different kinetic models for miglitol tablets.

TABLE 4: DIFFERENT KINETIC MODELS FOR MIGLITOL TABLETS

\begin{tabular}{|c|c|c|c|c|c|c|c|}
\hline \multirow{2}{*}{$\begin{array}{c}\text { Formulation } \\
\text { code }\end{array}$} & \multirow{2}{*}{$\begin{array}{c}\text { Zero Order } \\
\mathbf{R}^{2}\end{array}$} & \multirow{2}{*}{$\begin{array}{c}\text { First Order } \\
\qquad \mathbf{R}^{2}\end{array}$} & \multirow{2}{*}{$\begin{array}{c}\text { Higuchi } \\
\mathbf{R}^{2}\end{array}$} & \multicolumn{3}{|c|}{ Korsmeyer's - Peppas } & \multirow[b]{2}{*}{ Best fit model } \\
\hline & & & & $\mathrm{R}^{2}$ & $\mathrm{n}$ & $\mathrm{k}$ & \\
\hline F1 & 0.863 & 0.952 & 0.961 & 0.978 & 0.467 & 1.403 & Korsmeyer's - Peppas \\
\hline F2 & 0.853 & 0.955 & 0.953 & 0.960 & 0.485 & 1.366 & Korsmeyer's - Peppas \\
\hline $\mathbf{F 3}$ & 0.827 & 0.977 & 0.934 & 0.923 & 0.521 & 1.295 & First Order \\
\hline F4 & 0.786 & 0.967 & 0.913 & 0.943 & 0.423 & 1.477 & First Order \\
\hline F5 & 0.805 & 0.964 & 0.925 & 0.941 & 0.491 & 1.393 & First Order \\
\hline F6 & 0.817 & 0.924 & 0.931 & 0.937 & 0.580 & 1.288 & Korsmeyer's - Peppas \\
\hline
\end{tabular}

RESULT AND DISCUSSION: In present work an attempt has been made to formulate controlled release matrix tablets of miglitol using three retardants namely hydroxypropyl methylcellulose used as primary rate controlling polymer and effect on in vitro drug dissolution were studied by addition of hydroxypropyl cellulose and hydroxyethyl cellulose different concentrations and combinations.

\section{Physical characterization of tablets: The} formulation of tablets was done by using direct compression technique which was found acceptable. All the formulations were prepared according to the formula given in table 1 . The prepared matrix tablets were evaluated for various physical properties as indicated in table 2 . The results of evaluation studies can be summarized as follows:

The thickness of the formulations was found to be in the range of $2.51 \pm 0.05 \mathrm{~mm}$ to $2.56 \pm 0.01 \mathrm{~mm}$. The crushing strength of all the tablets was in the range of $5.16 \pm 0.282 \mathrm{~kg} 5.47 \pm 0.318 \mathrm{~kg}$. The loss in total weight of the tablets due to friability was less than $0.5 \%$. The high value of crushing strength and low friability indicated that the compressibility of miglitol and adjuvant was good.

Drug content and in-vitro drug release of tablets: Drug content and in-vitro drug release studies are indicated in table 3. Drug content was found to be uniform among different formulation of tablets and ranged from $98.49 \pm 1.134 \%$ to $101.41 \pm 0.760 \%$. Invitro drug release studies revealed that formulations $\mathrm{F} 1, \quad \mathrm{~F} 2$ and $\mathrm{F} 3$ containing combination of hydroxypropylmethylcellulose and hydroxypropyl cellulose showed release of $85 \pm 0.02,80 \pm 0.08$ and $75 \pm 0.13$ respectively at the end of 12 hours. Cumulative release decreased as the concentration of polymer increased. Decrease in release indicates rate controlling effect of hydroxypropylcellulose in addition to hydroxypropylmethylcellulose. Also the standard deviation is low which is usually observed by using single hydroxypropylmethylcellulose in similar concentration. In-vitro drug release studies revealed that formulations F4, F5 and F6 containing combination of hydroxypropylmethylcellulose and hydroxyethylcellulose showed release of $89+0.25$, $88+0.28$ and $88+0.31$ respectively at the end of 12 hours. There is no significant decrease in cumulative percent release indicating no additional retarding effect of hydroxyethylcellulose in addition to hydroxypropylmethylcellulose.

Kinetics of drug release: There are various applied mathematical models for dissolution data of miglitol controlled release tablet are shown in table 4. Formulations F1, F2 and F6 have Korsmeyer's Peppas as best fit kinetic model for drug release. Formulations F1 and F2 follow Fickian mechanism for drug transport indicating drug release follows the diffusion process as described by Ficks $2^{\text {nd }}$ law of diffusion through thin films and is generally observed when water diffusion controls the drug release process whereas formulation F6 follows anomalous mechanism for drug transport indicating drug release deviates from Fick's law and where drug release is both diffusion and swelling controlled. 
Formulations F3, F4 and F5 have First Order as best fit kinetic model for drug release indicating the percentage of drug dissolved at a certain time point may be equivalent to the percentage surface area at that time point.

CONCLUSION: Results of present research work demonstrate that the combination of hydrophilic polymers was successfully employed for formulation of miglitol controlled release tablets. It is observed that combination of polymers produce a more linear release from matrix tablets with low standard deviation. Hydroxypropyl methylcellulose and hydroxypropyl cellulose in the concentration of $40 \%$ to the total polymer concentration is promising concentration for oral controlled release tablets of miglitol and that can be further give release above 12 hours. In all the formulations, drug release rate is inversely proportional to the concentration of polymer.

From this study, it is possible to design promising oral controlled release matrix tablets containing miglitol for the treatment of type 2 diabetes mellitus diseases with more efficacy and better patient compliance.
ACKNOWLEDGEMENT: The authors are sincerely thankful to Meyer Organics Pvt. Limited (Thane, India) for providing infrastructure facilities to carry out this research work.

\section{REFERENCES:}

1. Yie WCand Senshang L: Drug Delivery: Controlled Release. Encyclopaedia of Pharmaceutical Technology, Informa Healthcare, USA, Edition 3, Vol. 2, 2007:1082-1103.

2. Salsa T, Veiga Fand Pina ME: Cellulose ether polymers in hydrophilic matrices. Drug Development and Industrial Pharmacy 1997; 23:92-93.

3. Kumar G, Juyal V and Badoni PP: Formulation and evaluation of matrix tablets of acarbose. Drug Invention Today 2010; 2(5):264-267.

4. Kumar G, Juyal V and Badoni PP: Formulation and release kinetic study of hydrogel containing acarbose using polymers as hydroxypropyl methylcellulose and guar gum. Journal of Pharmaceutical Research 2009; 2(3):370-374.

5. Robinson JR and Lee VHL: Controlled Drug Delivery. Marcel Dekker Inc, New York, Edition 2, 1987:29-30.

6. Hogan JE: Hydroxypropyl methylcellulose sustained release technology. Drug Development and Industrial Pharmacy 1989; 15:975-999.

7. Pena R, Verain: Analysis of different parameters of an optimized prolonged release formulation obtained by five processes. Pharmaceutical Technology - Controlled Drug Release. Ellis Horwood, London, Vol. 2, 2005: 57-70.

8. Ibrahim FA, Ali FA and Ahmed SM: Kinetic Determination of Acarbose and Miglitol in Bulk and Pharmaceutical Formulation using Alkaline Potassium Permanganate. International Journal of Biomedical Science 2007; 3: 20-30.

9. Costa P, Manuel J and Lobo S: Modeling and comparison of dissolution profiles. European Journal of Pharmaceutical Sciences 2001; 13:123-133.

\section{How to cite this article:}

Ashtamkar J, Nangude S and Chugh N: Formulation and Evaluation of Controlled Release Tablets of Miglitol using combination of Hydrophilic polymers. Int J Pharm Sci Res 2013; 4(5); 1833-1837. 